\title{
Rice nitrate transporter OsNPF7.2 positively regulates tiller number and grain yield
}

\author{
Jie Wang ${ }^{1}$, Kai Lu', Haipeng Nie ${ }^{1,2}$, Qisen Zeng ${ }^{1,2}$, Bowen $W_{u^{1}}$, Junjie Qian ${ }^{1}$ and Zhongming Fang ${ }^{1,2^{*}}$ (D)
}

\begin{abstract}
Background: Rice tiller number is one of the most important factors that determine grain yield, while nitrogen is essential for the crop growth and development, especially for tiller formation. Genes involved in nitrogen use efficiency processes have been identified in the previous studies, however, only a small number of these genes have been found to improve grain yield by promoting tillering.

Results: We constructed over-expression (OX) lines and RNA-interference (Ri) lines, and selected a mutant of OsNPF7.2, a low-affinity nitrate transporter. Our analyses showed that rice tiller number and grain yield were significantly increased in OX lines, whereas Ri lines and mutant osnpf7.2 had fewer tiller number and lower grain yield. Under different nitrate concentrations, tiller buds grew faster in OX lines than in WT, but they grew slower in Ri lines and mutant osnpf7.2. These results indicated that altered expression of OsNPF7.2 plays a significant role in the control of tiller bud growth and regulation of tillering. Elevated expression of OSNPF7.2 also improved root length, root number, fresh weight, and dry weight. However, reduced expression of OSNPF7.2 had the opposite result on these characters. OsNPF7.2 OX lines showed more significantly enhanced influx of nitrate and had a higher nitrate concentration than WT. The levels of gene transcripts related to cytokinin pathway and cell cycle in tiller bud, and cytokinins concentration in tiller basal portion were higher in OX lines than that in WT, suggesting that altered expression of OsNPF7.2 controlled tiller bud growth and root development by regulating cytokinins content and cell cycle in plant cells. Altered expression of OsNPF7.2 also was responsible for the change in expression of the genes involved in strigolactone pathway, such as D27, D17, D10, Os900, Os1400, D14, D3, and OsFC1.
\end{abstract}

Conclusion: Our results suggested that OSNPF7.2 is a positive regulator of nitrate influx and concentration, and that it also regulates cell division in tiller bud and alters expression of genes involved in cytokinin and strigolactone pathways, resulting in the control over rice tiller number. Since elevated expression of OSNPF7.2 is capable of improving rice grain yield, this gene might be applied to high-yield rice breeding.

Keywords: Rice, OsNPF7.2, Tiller bud, Cytokinin, Tiller number, Grain yield

\section{Background}

Rice (Oryza sativa L.) is one of the three major grain crops grown worldwide and is consumed by more than half of the world's population (Khush 2005). The rapid increase of the human population puts high demand on rice production, meanwhile high rice yield is a target pursued by plant breeders. Rice yield is mainly controlled by three factors: panicle number per plant, grain number per panicle, and thousand-grain weight. Panicle

\footnotetext{
* Correspondence: zmfang@mail.hzau.edu.cn

${ }^{1}$ Center of Applied Biotechnology, Wuhan Institute of Bioengineering, Wuhan 430415, China

${ }^{2}$ National Key Laboratory of Crop Genetic Improvement, Huazhong Agricultural University, Wuhan 430070, China
}

number per plant is dependent on the ability of plant to produce tillers (Liang et al. 2014). Starting with shoot branching, rice tiller experience two distinct stages in its development: the formation of an tiller bud at each leaf axil and the outgrowth of the tiller bud (Li et al. 2003; Xing and Zhang 2010). Therefore, final tiller number is determined not only by the number of tiller bud but also by outgrowth rate of tiller bud (Wang and Li 2011). In the past few years, many quantitative trait loci (QTLs) and genes involved in tiller bud formation and outgrowth in rice have been identified, such as $M O C 1$ ( $\mathrm{Li}$ et al. 2003), MOC2 (Koumoto et al. 2013), MOC3/SRT1 (Lu et al. 2015; Mjomba et al. 2016), TAD1/TE (Xu et al. 2012; Lin et al. 2012), LAX1 (Oikawa and Kyozuka 2009), LAX2 
(Tabuchi et al. 2011), OsTB1/OsFC1 (Takeda et al. 2003; Minakuchi et al. 2010), especially, the genes responsible for strigolactone pathways, such as D27 (Lin et al. 2009), D17/OsCCD7/HTD1 (Zou et al. 2005; Zou et al. 2006; Kulkarni et al. 2014; Yang et al. 2017), D10 (Arite et al. 2007), D14 (Arite et al. 2009), D3 (Ishikawa et al. 2005; Yoshida et al. 2012), and D53 (Zhou et al. 2013; Jiang et al. 2013).

Tiller bud outgrowth is regulated not only by endogenous factors, but also by environmental signals (Xing and Zhang 2010). Nitrogen (N), as an important environmental factor, affects rice growth and development including rice tillering. Nitrate is the major form of $\mathrm{N}$ available in aerobic environments and many members of nitrate transporter gene families are found in rice, such as 80 NPFs (NRT1/PTRs: NRT1, low-affinity nitrate transporter; PTR, di/tripeptide transporter), 5 NRT2s, and 2 NAR2s members. To date, only a few NPF members have been characterized in rice (Li et al. 2017). OsNRT1 (OsNPF8.9) was first described and found to function as a low affinity nitrate transporter (Lin et al. 2000). Afterwards, other NPFs were explored, such as SP1 (OsNPF4.1) and OsPTR9 (OsNPF8.20), however, their substrates remain unclear (Lin et al. 2000; Fang et al. 2013), Recently, OsNPF2.4, OsNPF2.2, and OsNPF7.2 have been reported to serve as low-affinity nitrate transporters functioning under high nitrate concentrations ( $\mathrm{Li}$ et al. 2015; Xia et al. 2015; Hu et al. 2016). Allelic differences in the dual-affinity nitrate transporter NRT1.1B (OsNPF6.5) have been reported between indica and japonica cultivars with high nitrogen-use efficiency and grain yield in the NRT1.1Bindica allele (Hu et al. 2015). OsPTR6 (OsNPF7.3) transports di/tripeptides Gly-His and Gly-His-Gly and its high levels of expression enhance rice growth (Fan et al. 2014). A recent study reveals that OsNPF7.3 is induced by organic nitrogen, and that elevated expression of OsNPF7.3 increases the number of panicles per plant, filled grain numbers per panicle, grain nitrogen content, and enhances grain yield (Fang et al. 2017). OsPTR7 (OsNPF8.1) shows dimethylarsenate (DMA) transport activity and is involved in the long-distance translocation of DMA into rice grain (Tang et al. 2017).

Of all the characterized NPF transporters to date, only OsNPF8.20, OsNPF6.5, and OsNPF7.3 can moderate rice tiller number and enhance grain yield (Fang et al. 2013; $\mathrm{Hu}$ et al. 2015; Fang et al. 2017). It is unclear whether other NPF genes play a role in rice tillering, especially by regulating $\mathrm{N}$ and phytohormones in plant cells. One previous study showed that knock-out of OsNPF7.2 retarded rice root growth under high nitrate supply $(\mathrm{Hu}$ et al. 2016). However, the effect of increased expression of OsNPF7.2 on rice growth and development is yet unknown, neither is the influence agronomic traits. This study analysed over-expression lines (OX), RNA-interference lines (Ri), and a mutation of OsNPF7.2 and found that overexpression of OsNPF7.2 significantly increased rice tiller number by promoting tiller bud elongation and by regulating cytokinin (CK) and strigolactone (SL) pathway in cells.

\section{Results \\ Over-expression of OsNPF7.2 improves rice tiller number and grain yield}

OsNPF7.2 is mainly expressed in the roots of seedlings, and its protein transports nitrate at vacuolar membrane (Hu et al. 2016). In order to investigate the effects of the altered expression of OsNPF7.2 on rice growth and development, we constructed over-expression (OX) lines and RNA-interference (Ri) lines; we also analysed knock-out mutant osnpf7.2. We found that tiller number increased in three OX lines at reproductive stage (Fig. 1b-d, r) compared to that in wild-type (WT) ZH11 (Fig. 1a, r), but it dramatically decreased in three Ri lines (Fig. 1e-g, r) and mutant osnpf7.2 (Fig. 1h, r). Three OX lines also had a higher total grain number per plant than WT (Fig. 1i-l, t), whereas Ri lines had a lower total grain number per plant than WT (Fig. 1m-o, t). The total grain number of mutant osnpf7.2 was less than half of that of WT (Fig. 1p, t). It was confirmed that the formation of phenotype resulted from the altered expression of OsNPF7.2 by using qRTPCR in different transgenic lines (Fig. 1a-h and q). Overall, our results indicated that elevated OsNPF7.2 expression level significantly enhanced the total grain number per plant.

The number of panicles derived from rice tillers is one of the three key factors determining rice grain yield (Xing and Zhang 2010). The analysis of panicle number in the transgenic lines presented similar change trend of tiller number as described above (Fig. 1s). Moreover, there was no significant difference in 1000-grain weights among different transgenic lines of OsNPF7.2 (Fig. 1u). Grain yield per plant in OX lines was significantly greater than that in WT (Fig. 1v). Thus, over-expression of OsNPF7.2 significantly increased rice tiller number and total grain number per plant, while down-regulation of OsNPF7.2 produced the opposite effects.

\section{Elevated expression of OsNPF7.2 promotes rice tiller bud outgrowth especially under high nitrate concentrations} We further investigated the regulatory effort of OsNPF7.2 on rice tillering by analysing of the development of tiller buds in WT, OX lines, Ri lines, and mutant osnpf7.2 grown under different nitrate concentrations $(0.5-8 \mathrm{mM})$. Tiller buds grew more rapidly in OX lines than in WT under all nitrate concentrations with this phenomenon observed continuously for 34 days after germination (DAG); tiller buds growth was slower in line Ri and mutant osnpf7.2 than in WT (Fig. 2a-e). OX lines had significantly longer tiller buds than WT when plants were treated with $0.5 \mathrm{mM}$ nitrate at 19-34 DAG (Fig. 2f). However, no significant difference in buds length between 


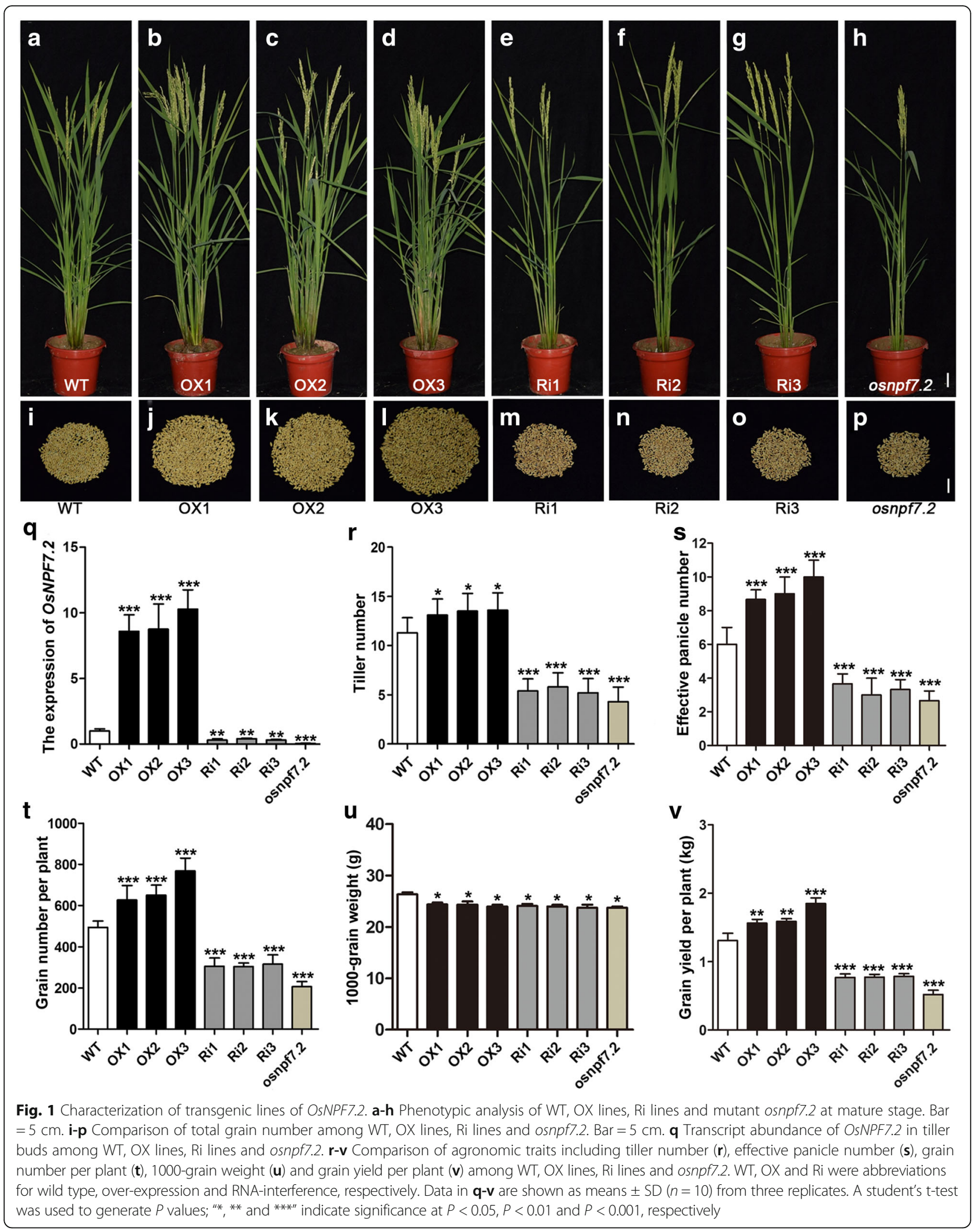



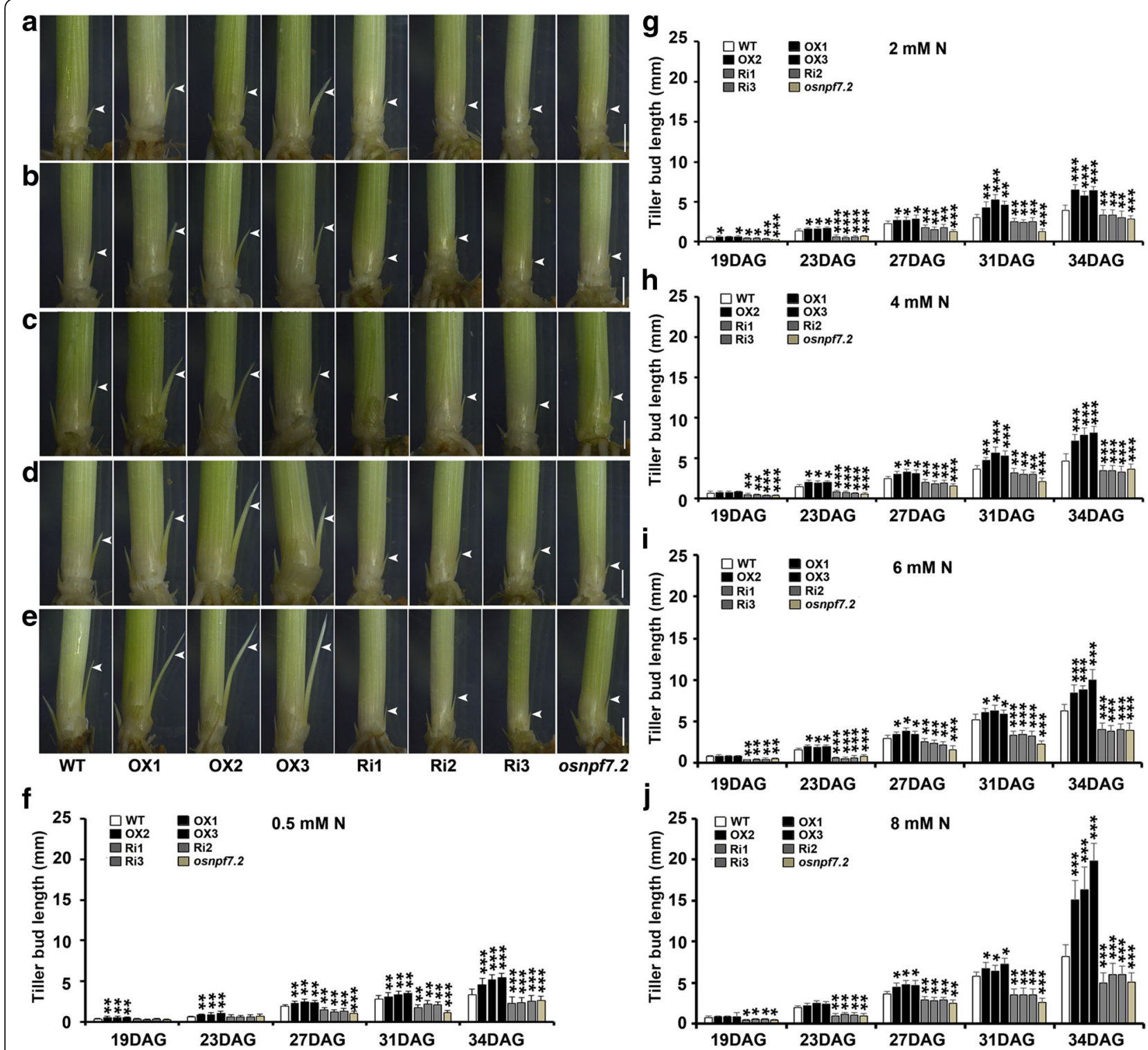

Fig. 2 Altered expression of OSNPF7.2 regulated tiller bud outgrowth under the different nitrate concentration. a-e Comparison of tiller buds among WT, OX lines, Ri lines and osnpf7.2 under the $0.2 \mathrm{mM} \mathrm{NaNO}_{3}, 2 \mathrm{mM} \mathrm{NaNO}_{3}, 4 \mathrm{mM} \mathrm{NaNO} 3,6 \mathrm{mM} \mathrm{NaNO}_{3}$ and $8 \mathrm{mM} \mathrm{NaNO}_{3}$, respectively. White arrows indicated tiller buds, bar $=1 \mathrm{~mm}$. $\mathbf{f - j}$ Statistical analysis of the tiller buds length among WT, OX lines, Ri lines and osnpf7.2 under the $0.2 \mathrm{mM} \mathrm{NaNO}_{3}, 2 \mathrm{mM} \mathrm{NaNO}_{3}, 4 \mathrm{mM} \mathrm{NaNO}_{3}, 6 \mathrm{mM} \mathrm{NaNO}_{3}$ and $8 \mathrm{mM} \mathrm{NaNO}_{3}$, respectively. DAG was the abbreviation of days after germination. Values in $\mathbf{f}-\mathbf{j}$ are shown as mean $\pm \mathrm{SD}(n=20)$ from three replicates; "**" "***" and "***" indicated significant differences at $P<0.05, P<0.01$ and $P<0.001$, respectively

line OX and WT was observed under high nitrate concentrations (4-8 mM) at 19 DAG (Fig. 2h-j). OX lines had longer tiller buds than WT after 27 DAG at all nitrate concentrations, and the maximum length of tiller buds in OX lines were found at 34 DAG in plants treated with $8 \mathrm{mM}$ nitrate (Fig. 2j). Significantly shorter tiller buds were observed in Ri lines than in WT (Fig. 2f-j). Based on these results, it could be concluded that elevated expression of OsNFP7.2 promoted rice tiller bud outgrowth, especially under high nitrate concentrations, between 19 and 34 DAG.
Elevated expression of OsNPF7.2 benefits rice seedling growth and root development

Next, we investigated the effect of up-regulation of OsNPF7.2 on rice seedling growth and development in hydroponic cultures under different nitrate concentrations. Seedlings of OX lines under $8 \mathrm{mM} \mathrm{NaNO}_{3}$ conditions produced stronger culms than seedlings of WT (Fig. 3a). However, Ri lines and mutant osnpf7.2 showed the opposite result (Fig. 3a). Root morphology is important for plant to optimize $\mathrm{N}$ absorption from the soil 


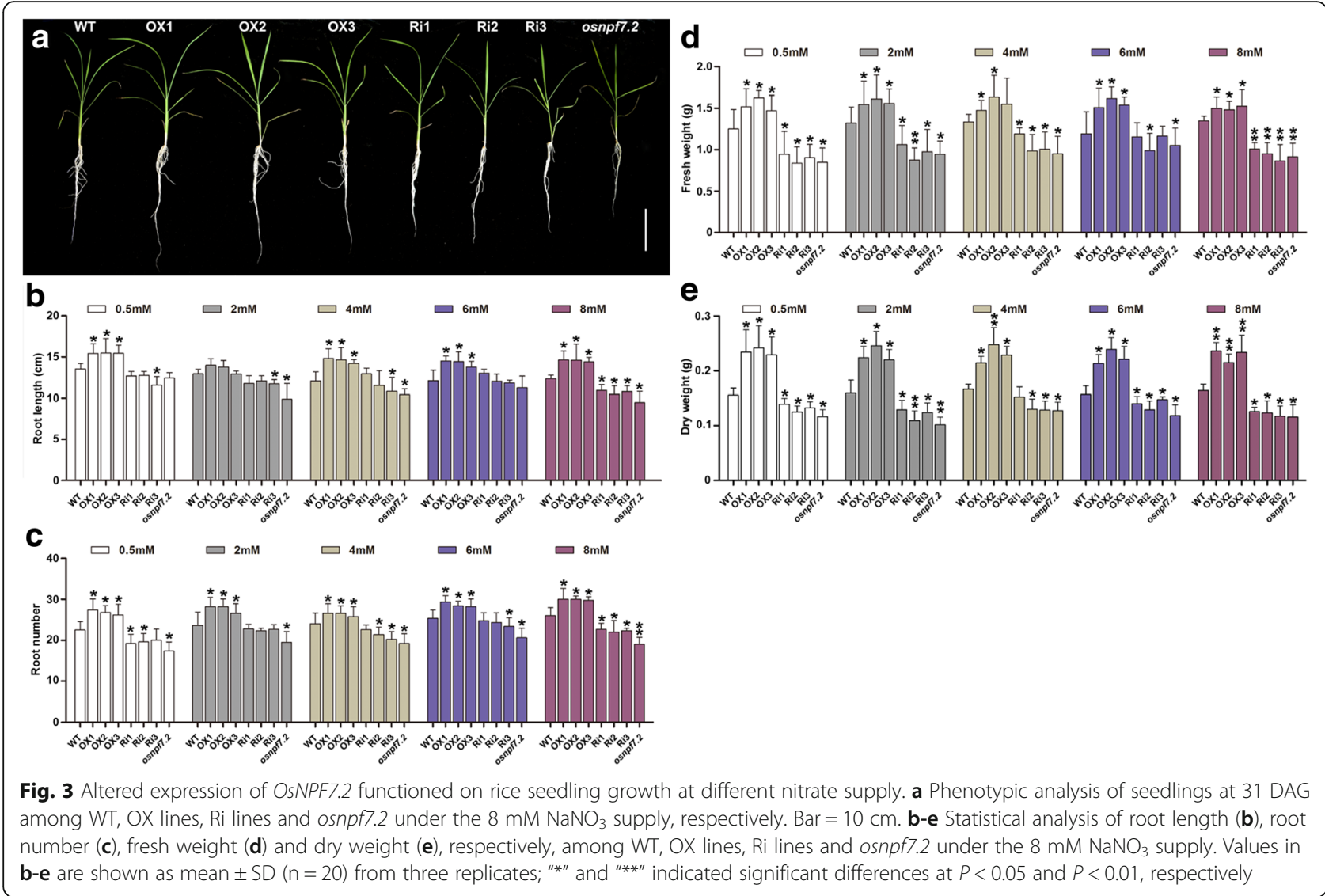

through its responses to nitrates (Hachiya and Sakakibara 2017), we examined root development in OsNPF7.2 transgenic lines. In Ri lines and mutant osnpf7.2, root growth was inhibited resulting in their roots were shorter than those of WT seedlings (Fig. 3a-b). The comparison of root number revealed that elevated expression of OsNPF7.2 caused a significant increase at all nitrate concentrations, while downregulated expression of OsNPF7.2 result in a significant decrease of root number at $8 \mathrm{mM} \mathrm{NaNO}_{3}$ (Fig. 3c). Compared with those of WT, the fresh weight and dry weight of OX lines were significantly increased (Fig. 3d-e). These results demonstrated that genetically modification of OsNPF7.2 could significantly influence rice root development.

We also cultured the different lines under $4 \mathrm{mM}$ $\left(\mathrm{NH}_{4}\right)_{2} \mathrm{SO}_{4}$, and found no significant difference in root length among WT, OX lines, Ri lines, and mutant osnpf7.2 at the seedling stage (40 DAG, Additional file 1 Figure S1b and $\mathrm{d}$ ). However, root length of OX lines exceeded that of WT when seedlings were treated with $8 \mathrm{mM}$ $\mathrm{NaNO}_{3}$, whereas root length of the seedlings with down-regulated OsNPF7.2 expression decreased (Additional file 1 Figure $\mathrm{Sla}$ and $\mathrm{c}$ ). These results indicated that OsNPF7.2 transgenic seedlings responded to environmental nitrate by altering root growth and development, but they did not respond to ammonium.

\section{Changes in expression of OsNPF7.2 influence the rate of $\mathrm{NO}_{3}^{-}$influx and concentration}

Seedlings with various expression lines were treated under nitrogen starvation conditions for a week, and then were cultured with a solution containing $8 \mathrm{mM} \mathrm{ni-}$ trate for $24 \mathrm{~h}$. The amount of $\mathrm{NO}_{3}^{-}$obsorbed by seedlings was then measured. The rate of $\mathrm{NO}_{3}^{-}$influx into roots of OX lines was higher than that of WT (Fig. 4a), indicating that elevated expression of OsNPF7.2 enhanced nitrate uptake by roots. In OX lines, we also detected a higher rate of $\mathrm{NO}_{3}^{-}$influx into the leaf sheath and leaf blade, implying that elevated expression of OsNPF7.2 promoted the translocation of $\mathrm{NO}_{3}^{-}$from roots to leaf sheath (Fig. 4a). Besides, we measured nitrate concentration of root, leaf sheath and leaf blade in the seedlings with different expression lines. The detected nitrate concentration was consistent with the rate of $\mathrm{NO}_{3}^{-}$influx in different lines (Fig. 4b). Total nitrogen concentrations in root, leaf sheath, and leaf blade did not differ significantly among WT, OX lines, Ri lines, and mutant osnpf7.2 (data not shown). However, total nitrogen content in those lines with up-regulated expression became higher than that in WT, and repression lines exhibited lower total nitrogen content compared to WT (Fig. 4c). These results demonstrated that over- 


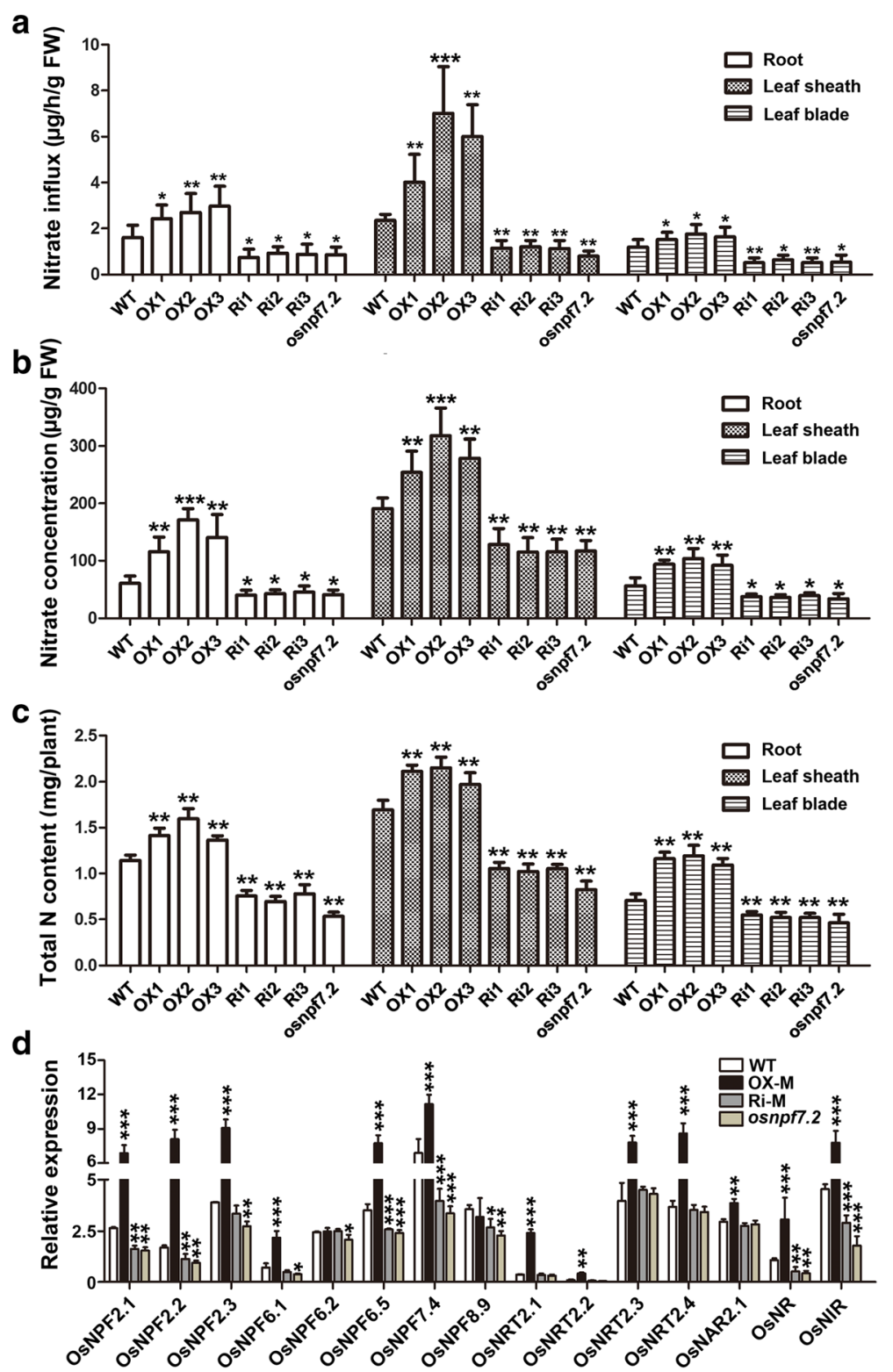

Fig. 4 OsNPF7.2 influenced $\mathrm{NO}_{3}^{-}$influx, $\mathrm{NO}_{3}^{-}$concentration and total nitrogen content among transgenic lines. a Analysis of $\mathrm{NO}_{3}^{-}$influx rate among WT, OX lines, Ri lines and osnpf7.2 cultured under $6 \mathrm{mM} \mathrm{NaNO}$ supply. b NO- concentration of WT, OX lines, Ri lines and osnpf7.2 cultured under $6 \mathrm{mM} \mathrm{NaNO}_{3}$ supply. c Comparison of total nitrogen content among WT, OX lines, Ri lines and osnpf7.2 cultured under 6 mM $\mathrm{NaNO}_{3}$ supply. $\mathbf{d}$ Expression level of crucial genes involved in absorbing, transporting and assimilation of nitrate among WT, OX-M, Ri-M and osnpf7.2 cultured under $6 \mathrm{mM} \mathrm{NaNO}_{3}$ supply. OX-M and Ri-M indicated that mixed equal-amount RNA which extracted from 10 seedlings' tiller buds of each three OX lines and Ri lines, respectively. Date are shown as mean \pm SD $(n=10)$ from three replicates; " ${ }^{* *}$, "***" and "****" indicated significant differences at $\mathrm{P}<0.05, \mathrm{P}<0.01$ and $\mathrm{P}<0.001$, respectively

expression of OsNPF7.2 promoted translocation of nitrate from roots to leaf sheath, and enhanced nitrate influx and concentration.

We detected the effect of OsNPF7.2 various expression lines on expression levels of 18 genes, including low-affinity nitrate transporters, high-affinity nitrate transporters, nitrate and ammonium assimilation genes. The expression level of 7 NPF genes including OsNPF6.5 in OX lines was increased compared to that in WT (Fig. 4d). Two of the 18 genes, OsNPF6.5 and OsGS1;2, were reported to promote tiller bud outgrowth and the increase in rice tiller number ( $\mathrm{Hu}$ et al. 2015; Ohashi et al. 2017). Expression of both OsNPF6.5 and OsGS1;2 was upregulated in OX lines and down-regulated in Ri lines and mutant osnpf7.2 (Additional file 2 Figure S2). Based on these results, it could be concluded that elevated expression 
of OsNPF7.2 promotes nitrate uptake and assimilation by regulating other nitrate-related transporters and enzymes.

\section{OsNPF7.2 regulates cell proliferation in tiller bud by coordinating cytokinin and strigolactone pathways}

Shoot branching (tiller) is regulated by plant hormones, particularly cytokinins (CKs) and strigolactones (SLs). It was reported that CKs promote tillering in rice, whereas SLs inhibit it (Leyser 2003; Ferguson and Beveridge 2009; Hayward et al. 2009; Shimizu-Sato et al. 2009; Xu et al. 2015). To investigate the possible interaction between nitrogen and plant hormones, we measured the expression levels of the important genes responding to CK and SL pathways in the rice tiller bud with various transgenic lines. Over-expression of OsNPF7.2 resulted in the upregulated expression of OsIPTs, LONELY GUY (LOG), and CK-response regulators (OsARRs/OsRRs) (Fig. 5a). Levels of cytokinins were regulated through the irreversible oxidative cleavage of the $\mathrm{N}^{6}$-side chain by CYTOKININ DEHYDROGENASE/OXIDASE (CKXs) (Zurcher and Muller 2016). Based on their report, we measured gene expression of $10 C K X s$, and found half of OsCKXs exhibited lower expression level in OX lines compared to that in WT, whereas higher expression level in both Ri lines and mutant than that in WT (Fig. 5b). Additionally, we also detected the content of four CKs (iP, tZ, cZ and DZ) in tiller basal portion among different genetically modified lines. Compared to WT, OX lines exhibited a significant increase in the concentration of iP and $\mathrm{tZ}$, while Ri lines and mutant showed a little but not significant decrease in the concentration of iP and a significant decrease in the concentration of $\mathrm{tZ}$ (Fig. $5 \mathrm{c}$ ). These results suggested that altered expression of OsNPF7.2 controlled tiller bud outgrowth possibly by regulating CKs content in the tiller bud. Cytokinins function mainly by stimulating cell division and growth and by promoting cell differentiation as

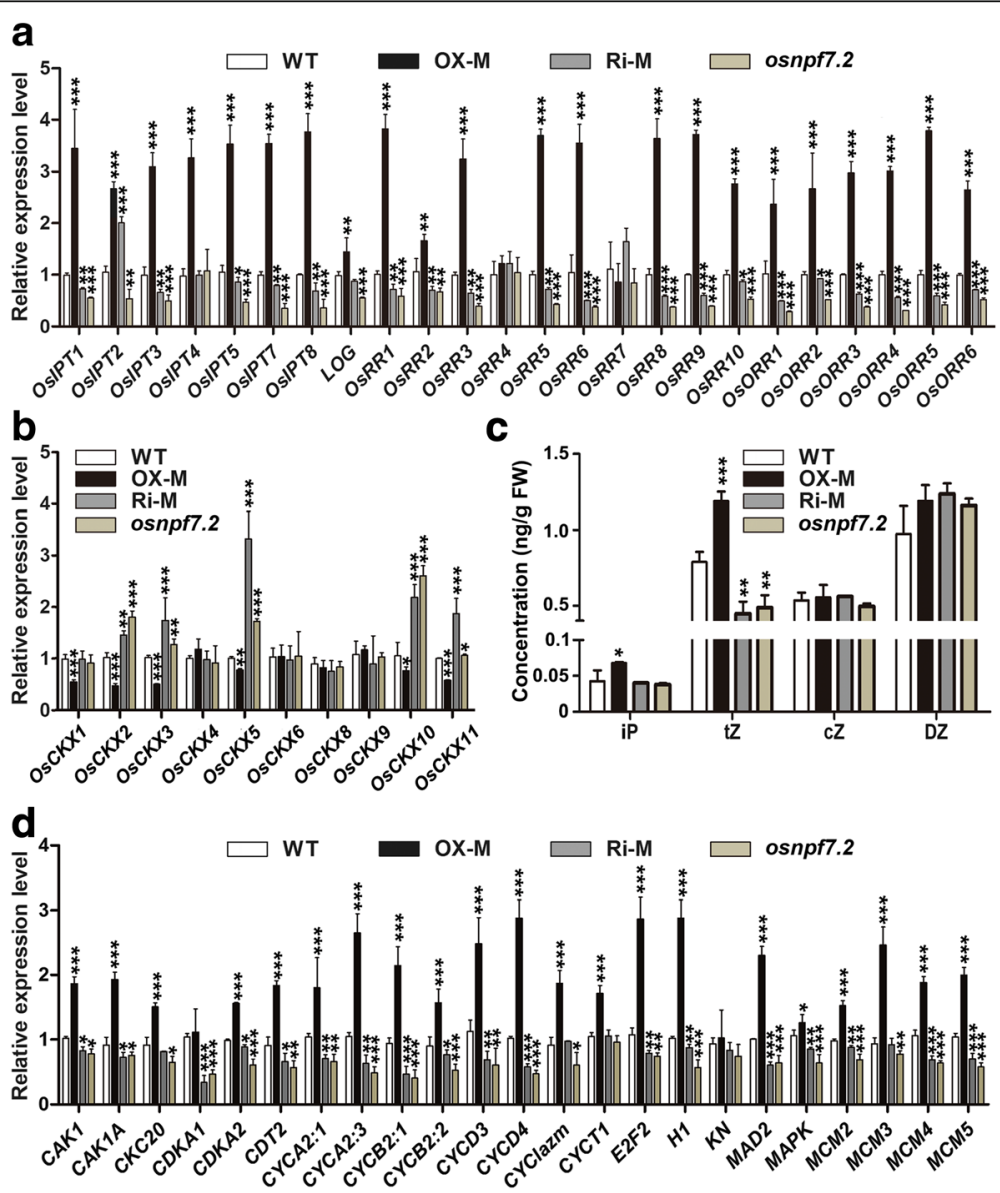

Fig. 5 Altered expression of OsNPF7.2 regulated CKs concentration and cell cycle. a Expression level of rice genes involved in cytokinin synthesis and response in tiller buds of seedlings at 34 DAG among WT, OX-M, Ri-M and osnpf7.2. b Expression of 10 CKXs at 34 DAG among WT, OX-M, RiM and osnpf7.2. c CK free base concentration in seedling tiller basal portion at 34 DAG among WT, OX-M, Ri-M and osnpf7.2. c Comparison of genes involved in cell cycle in tiller buds of seedlings at 34 DAG among different transgenic lines. OX-M and Ri-M in (a)-(b) and (d) was identical to that in fig. 4d. OX-M and Ri-M in (c) indicated tiller basal portion (about $0.5 \mathrm{~cm}$ ) mixed from 30 seedlings of each OX lines and Ri lines, respectively. Date are shown as mean \pm SD from three replicates; " ${ }^{* *}$, "***" and " $" * * * "$ indicated significant differences at $P<0.05, P<0.01$ and $P<0.001$, respectively 
well (Zurcher and Muller 2016). However, cell proliferation is strictly controlled by the major regulators: cyclindependent kinases (CDKs) and their regulatory partner cyclins (Yamaguchi et al. 2003). We measured the expression levels of selected genes involved in cell cycle. Significant up-regulation of OsNPF7.2 was associated with an increased expression level of $C D K s$ and cyclin genes such as CYCAs, CYCBs and CYCDs. By contrast, Ri lines and mutant osnpf7.2 showed decreased expression of these genes (Fig. 5d). We also found that the expression patterns of four minichromosome maintenance genes (MCM2, $M C M 3, M C M 4$ and MCM5) were similar to those of cyclin genes in the transgenic lines (Fig. 5d). These results indicated that elevated expression of OsNPF7.2 promoted tiller bud growth possibly by accelerating plant cell proliferation.

SL biosynthesis (D27, D17, D10, Os900 and Os1400), perception (D14 and D3), and signalling (D53) were reported to have participated in the regulation of tiller bud outgrowth (Jiang et al. 2013; Zhou et al. 2013; Liang et al. 2014; Zhang et al. 2014). These SL synthesis and signalling genes were also detected in tiller bud in the different transgenic lines. The genes $(D 27, D 17, D 10, D 14$, and D3) were down-regulated in OX lines but upregulated in Ri lines (Fig. 6). Besides, two members of CYP711 enzymes (Os900 and Os1400, Zhang et al. 2014) showed similar expression pattern to that of D27, D17, D10, D14, and D3 (Fig. 6). However, expression level of D53, a repressor of SL signalling, exhibited no significant differences among WT, OX lines, Ri lines, and mutant (Fig. 6). It was reported that the interaction between OsMADS57 and OsFC1/OsTB1 targets D14 to control the outgrowth of tiller bud in rice (Guo et al. 2013). We compared the expression level of OsFC1 in tiller bud in the various transgenic lines and found that OsFC1 was down-regulated in OX lines and was up-regulated in $\mathrm{Ri}$ lines and mutant (Fig. 6). SLs, as most of the germination stimulants identified so far, function on stimulating germination of root parasitic plants such as witchweeds (Striga spp.) and broomrapes (Orobanche and Phelipanche spp., Yoneyama et al. 2010). We performed germination assay of Orobanche Cumana to estimate SLs level, and found that the germination rate of Orobanche Cumana seeds was higher when the seeds were treated with root exudates extracting from $\mathrm{Ri}$ lines and mutant osnpf7.2 than that from WT, and the opposite results were found when the seeds were treated with root exudates from OX lines (Additional file 3 Figure S3). These results indicated that altered expression of OsNPF7.2 might influence SL biosynthesis, which in turn influenced perception and signalling in rice tiller bud, therefore controlled rice tillering.

Based on these results, we propose a model in which altered expression of OsNPF7.2 participates in CK and SL pathways to modify rice tillering (Fig. 7). In OX lines, elevated expression of OsNPF7.2 is capable of enhancing CK accumulation and inhibiting SL accumulation. Hence, cell division in the tiller bud is promoted, which is favourable for rice tillering. However, down-regulation of OsNPF7.2 induces the opposite effects. Additionally, we suggest that OsNPF7.2 coordinates CK and SL pathways, and further regulates tiller bud, eventually controls rice tillering.

\section{Discussion \\ OsNPF7.2 positively regulates rice tiller number and grain yield}

Nitrogen is a crucial determinant of plant growth and grain yield (Hachiya and Sakakibara 2017; Li et al. 2017). Plants make use of transporters to take up nitrogen from the soil via the roots and transport it to other organs. Thus, the coordinated expression of transporter genes is essential to meet the plant growth's requirements for nitrogen. Up till now, only a few nitrate transporters of NPF family (OsNPF8.9, OsNPF2.2, OsNPF2.4, OsNPF6.5, and OsNPF7.2) have been characterized in rice (Lin et al. 2000; Li et al. 2015; Xia et al. 2015; Hu et al. 2016). Of these, only OsNPF6.5 regulates rice tiller number and promotes grain yield ( $\mathrm{Hu}$ et al. 2015). Our study revealed that elevated expression of OsNPF7.2 significantly

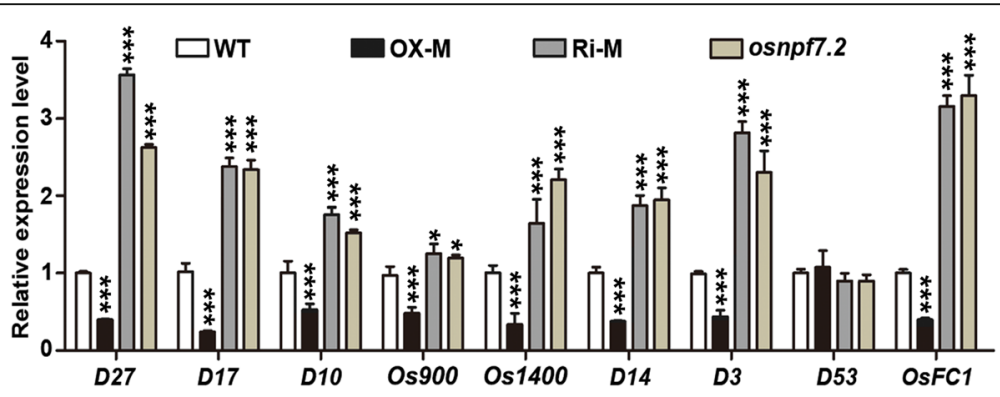

Fig. 6 Expression of genes involved in strigolactone biosynthesis, perception and signalling pathway. Genes' expression involved in SL biosynthesis (D27, D17, D10, Os900 and Os 1400), perception (D14 and D3), and signalling (D53) were detected among different genetical modified lines. OX-M and Ri-M was same to that in fig. $4 \mathrm{~d}$. Date are shown as mean \pm SD from three replicates; "**" and "***" indicated significant differences at $P<0.05$ and $P<0.001$, respectively 


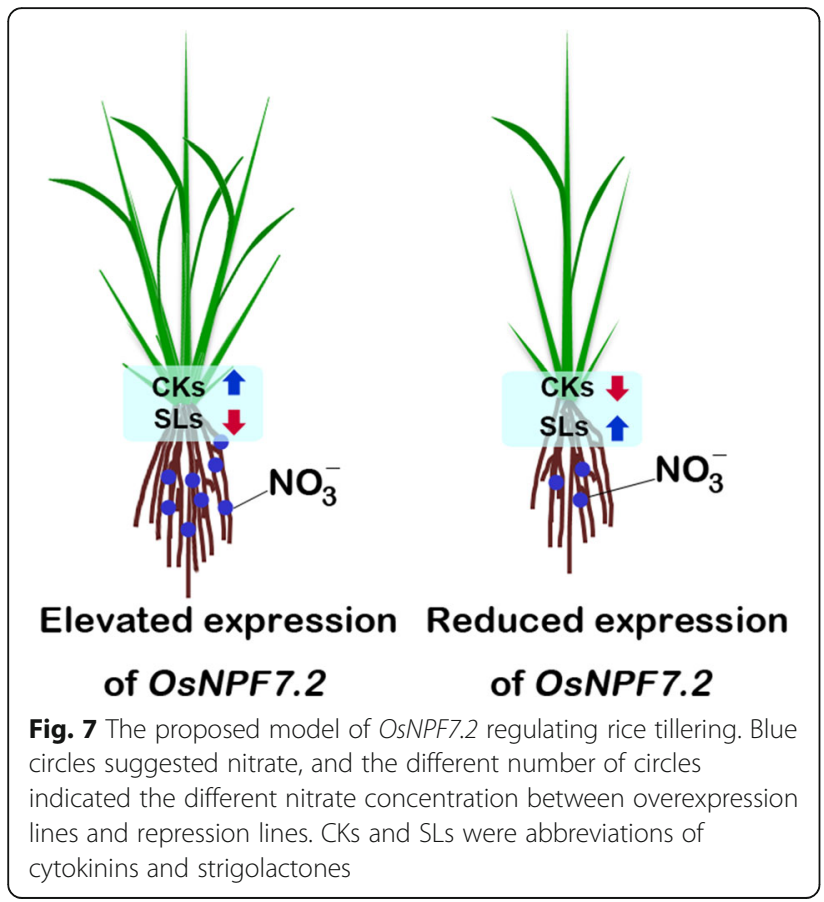

enhances tiller number, whereas repressed expression causes a reduction in tiller number (Fig. 1). However, previous study only reported the retarded growth of rice root of plant mutant osnpf7.2 (Hu et al. 2016). Rice tiller number was reported to be one of the most important agronomic traits determining panicle number and grain yield ( $\mathrm{Li}$ et al. 2003; Xing and Zhang 2010). The increased number of panicles resulted in a larger number of filled grain per plant in OX lines than in WT, which gave rise to an improved rice grain yield per plant (Fig. 1r-t and v). Interesting, 1000-grain weight among all genetically modified lines exhibited slight decreased compared with that in WT (Fig. 1u), which indicated that appropriate expression of OsNPF7.2 might be beneficial to increase grain weight. This study suggested that OsNPF7.2 may be useful to culture high-yield rice varieties.

\section{OsNPF7.2 influences $\mathrm{NO}_{3}^{-}$influx and concentration, and tiller bud growth}

One previous study reported that vacuolar-membranelocalized OsNPF7.2 could transport nitrate at a low affinity (Hu et al. 2016). Our study showed that overexpression of OsNPF7.2 enhanced the rate of $\mathrm{NO}_{3}^{-}$influx into roots, increased $\mathrm{NO}_{3}^{-}$concentration in root, and promoted the translocation of nitrate from roots to leaf sheath (Fig. 4a-c), indicating that elevated expression of OsNPF7.2 contributes to nitrate allocation between roots and shoots. Recently, three NRT1/NPF family members (NPF5.11, NPF5.12 and NPF5.16) in Arabidopsis were reported to be localized at vacuolar membrane and to play a possible role in modulating nitrate allocation between roots and shoots (He et al. 2017).
NRT1.1B-indica allele was reported to increase tiller number per plant, and to enhance grain yield per plant (Hu et al. 2015). Our study found that up-regulated expression of OsNPF7.2 significantly enhanced tiller bud growth, and that down-regulated expression of OsNPF7.2 impaired tiller bud development (Fig. 2), suggesting that the enhanced translocation of nitrate into leaf sheath in OX lines might contribute to faster growth of tiller bud determining rice tiller number. In addition, the biomass of OX lines was higher than that of WT (Fig. 3d-e), which might mainly be attributed to the increased tiller number at vegetative stage. Therefore, it can be concluded that elevated expression of nitrate transporter OsNPF7.2 not only promoted rice tillering at vegetative stage, but also played a potentially important role in increasing rice grain yield at reproductive stage.

Elevated of OsNPF7.2 promotes cell division and rice tiller formation through cytokinin and strigolactone pathways It has been reported that elevated CK level might promote tiller bud outgrowth (Turnbull et al. 1997). Our study indicated that the expression of such CK crucial genes as IPTs and LOG was higher in OX lines than in WT, suggesting that CKs probably produced in larger amounts in OX lines than in WT; however, the opposite result was found in Ri lines and in mutant (Fig. 5a). Furthermore, the expression pattern of CK response genes (OsARRs and OsRRs) was similar to IPTs expression pattern in transgenic lines. Moreover, the content of iP and tZ was higher in OX lines than in WT (Fig. 5c), which indicated that over-expression of OsNPF7.2 enhanced CK accumulation in tiller bud.

Nitrogen uptake, assimilation, and recycling in plant roots were reported to determine plant development and productivity (Yamaya and Kusano 2014). However, numerous plant developmental processes such as root meristem specification, vascular development, and shoot and root growth, are determined by CKs (Zurcher and Muller 2016). In addition, CKs are key phytohormones for cell division and growth (Riou-Khamlichi et al. 1999). This study illustrates that elevated expression of OsNPF7.2 promotes up-regulation of crucial genes in cell cycle (Fig. 5d), which indicated that over-expression of OsNPF7.2 might promote cell division. To explore the regulatory mechanism of OsNPF7.2, we analyse expression of the major regulators in cell cycle, namely, cyclindependent kinases (CDKs) and their regulatory partner cyclins. The analysis shows that up-regulation of OsNPF7.2 significantly increases the expression level of $C D K s$, while down-regulation of OsNPF7.2 reduces the level of expression of CDKs (Fig. 5c). Based on these results, we conclude that altered expression of OsNPF7.2 controls rice tillering by regulating CK contents, and further regulating the cell cycle in tiller bud. 
Recently, SLs have been reported to be important phytohormones inhibiting tiller bud outgrowth in various plant species (Gomez-Roldan et al. 2008; Umehara et al. 2008). Reduction of SL production, perception, and signalling results in faster outgrowth of tiller bud (Domagalska and Leyser 2011; Ruyter-Spira et al. 2013). This study found that D27, D17, D10, Os900, Os1400, D14, $D 3$, and OsFC1 were down-regulated in OX lines but up-regulated in Ri lines and mutant, compared to WT (Fig. 6). OX lines displayed reduced SL biosynthesis, perception, and signalling, whereas $\mathrm{Ri}$ lines and mutant showed increased SL signalling. Based on these results, we construct a model of altered expression of OsNPF7.2 function in rice tillering, in which over-expression of OsNPF7.2 enhances CK levels but might inhibit SL pathway, which results in increased tillering (Fig. 7). However, the reduced tiller number in $\mathrm{Ri}$ lines and mutant osnpf7.2 might have resulted from weaker CK and stronger SL signalling in their tiller bud.

\section{Conclusions}

In this study, we constructed transgenic lines with different expression level of OsNPF7.2 and found that elevated expression of OsNPF7.2 contributed to the enhancement of $\mathrm{NO}_{3}^{-}$influx rate and the increase of nitrate concentration in over-expression lines. Importantly, OsNPF7.2 positively regulated tiller bud outgrowth, probably by coordinating CK and SL pathways in plant cells.

\section{Methods}

\section{Generation of transgenic rice lines}

To construct OsNPF7.2-overexpressing lines, a 1726-bp OsNPF7.2 cDNA was inserted downstream of the $35 S$ promoter in pCAM1301 using BglII and AflII, to produce the p35S-OsNPF7.2 plasmid. To generate the OsNPF7.2-RNAi lines, two 323-bp fragments of OsNPF7.2 cDNA were amplified and inserted downstream of the Ubi-1 promoter in vector pTCK303 (Wang et al. 2004). All of the constructed plasmids were transferred into japonica rice variety 'Zhonghua 11' (ZH11) by the Agrobacterium-mediated transformation method (Hiei et al. 1997). Homozygous T2 generation of each transgenic lines screened with hygromycin at final concentration of $50 \mathrm{mM}$ for a week were chosen for further studies. Mutant osnpf7.2 in ZH11 background was obtained from the Rice Mutant Database of Huazhong Agricultural University (http://rmd.ncpgr.cn/), which was the same to that used in the previous study (Hu et al. 2016). The corresponding primers are listed in Additional file 4. Table S1.

\section{Plant cultivation and agronomic traits analysis}

For basic agronomic traits analysis, rice plants were grown in the paddy field from June to October at the rice experimental station of the Wuhan Institute of Bioengineering. Ten plants at a spacing of $16.5 \mathrm{~cm} \times 26.5 \mathrm{~cm}$ were planted in a row and 5 rows of each line were planted. At reproductive stage, 10 plants of each lines were randomly chosen to detect agronomic traits. The grain number per panicle was measured as the total number of grains per plant divided by the number of panicles per plant. The 1000-grain weight was calculated as the weight of the total grains per plant and divided by the grain number, then converted to 1000-grain weight. Grain yield was measured as the weight of total grains per plant.

To analyse OsNPF7.2 expression function in seedling growth and development under different nitrogen conditions, $\mathrm{ZH} 11, \mathrm{OX}, \mathrm{Ri}$, and osnpf7.2 seedlings at 7 DAG were cultured in basic nutrient solution $(\mathrm{pH}=5.8)$ for a week. The composition of the basic solution was as follows: $1 \mathrm{mM} \mathrm{NH} \mathrm{NO}_{3}, 0.32 \mathrm{mM} \mathrm{NaH} \mathrm{PO}_{4}, 0.51 \mathrm{mM}$ $\mathrm{K}_{2} \mathrm{SO}_{4}, 1 \mathrm{mM} \mathrm{CaCl}_{2}, 1.65 \mathrm{mM} \mathrm{MgSO}, 8.9 \mu \mathrm{M} \mathrm{MnSO}_{4}$, $0.5 \mu \mathrm{M} \mathrm{Na} \mathrm{MoO}_{4}, 18.4 \mu \mathrm{M} \mathrm{H} \mathrm{H}_{3}, 0.14 \mu \mathrm{M} \mathrm{ZnSO}$, $0.16 \mu \mathrm{M} \mathrm{CuSO}_{4}$ and $40 \mu \mathrm{M} \mathrm{FeSO}_{4}$. Then seedlings at 14 DAG were transferred to basic nutrient solutions supplemented with the following sole nitrogen source: $0.5 \mathrm{mM} \mathrm{NaNO}_{3}, 2 \mathrm{mM} \mathrm{NaNO}_{3}, 4 \mathrm{mM} \mathrm{NaNO}_{3}, 6 \mathrm{mM}$ $\mathrm{NaNO}_{3}, 8 \mathrm{mM} \mathrm{NaNO} 3$ and $4 \mathrm{mM}\left(\mathrm{NH}_{4}\right)_{2} \mathrm{SO}_{4}$. Each nutrient solution was renewed every three days. Daytime conditions in the greenhouse were $32{ }^{\circ} \mathrm{C}$, with light from a sodium lamp $(400 \mathrm{~W})$ for $14 \mathrm{~h}$; night-time conditions were $25{ }^{\circ} \mathrm{C}$, and dark for $10 \mathrm{~h}$. At $34 \mathrm{DAG}$, root length, root number, fresh weight and dry weight of each lines were measured. Besides, tiller buds of different lines (34 DAG) were obtained to detect the expression level of OsNPF7.2 and other phytohormone-related genes.

\section{Measurement of nitrate influx, nitrate concentration, and total nitrogen content}

To analyse the nitrate influx, nitrate concentration and total nitrogen content, ten seedlings at 7 DAG of $\mathrm{ZH} 11$, $\mathrm{OX}, \mathrm{Ri}$, and osnpf7.2 were cultured in basic nutrient solution for a week. They were then placed in basic nutrient solution without nitrogen for a week for nitrogenstarvation treatment. The nitrogen-starved seedlings were transferred to culture solution containing $8 \mathrm{mM}$ nitrate for $24 \mathrm{~h}$. Free $\mathrm{NO}_{3}^{-}$content analysis was carried out by homogenizing plant tissues in cold extraction buffer [50 mM Tris- $\mathrm{HCl}$ (pH 7.0), $10 \mathrm{mM}$ imidazole, and 0.5\% $(w / v) \beta$-mercaptoethanol]. The suspension was centrifuged at 12,000 rpm for $30 \mathrm{~min}$ and the supernatant was collected. Free $\mathrm{NO}_{3}^{-}$content was determined from a standard curve of $\mathrm{KNO}_{3}$ (Cai et al. 2009). $\mathrm{NO}_{3}^{-}$influx was calculated as the difference in $\mathrm{NO}_{3}^{-}$content between the $8 \mathrm{mM}$ nitrate-treatment and nitrate-starved plants in an hour. Total nitrogen content was determined using the semi-micro Kjeldahl method using a nitrogen analyser (Smart Chem 200, Westco, Italy). Three replicates of each assay were performed. 


\section{RNA isolation and qRT-PCR}

Total RNA was extracted from tiller buds using TRIzol reagent (Invitrogen, Beijing, China). First-strand cDNA was synthesized using random primers and MLV reverse transcriptase (TaKaRa Bio, Beijing, China). qRT-PCR reaction solution was prepared in a total volume of $20 \mu \mathrm{L}$, containing $2 \mu \mathrm{L}$ of the cDNA, $0.2 \mathrm{mM}$ of each primer, and $10 \mu \mathrm{L}$ of $2 \times$ SYBR green PCR master mix (Takara Co. Ltd., http://www.takarabiomed.com.cn/). Quantitative real-time PCR was performed using SYBR Green mix (TaKaRa Bio, Beijing, China) and the 7500 RT qPCR system (Applied Biosystems, Foster City, CA, United States). The rice Actin gene (LOC_Os03g50885) was used as the internal control, and three technical replicates were performed for each sample. Expression level was calculated using the relative quantification method (Carleton 2011). The primers used for qPCR are listed in Additional file 4.

\section{Extraction of root exudates and germination assay of Orobanche cumana seeds}

Rice seedlings at 7 DAG were cultured in basic nutrient solution with $6 \mathrm{mM} \mathrm{NaNO}$ supply for a month, then root exudates of $\mathrm{ZH} 11$, OX lines, Ri lines and osnpf7.2 seedlings were extracted using a modified method (Chen et al. 2017). The shoots $(5 \mathrm{~cm}$ above the roots) were excised with a razor, and the xylem sap was collected for $12 \mathrm{~h}$ after decapitation of the shoots. Root exudates were then diluted with distilled water for 10 times to stimulate Orobanche cumana seeds germination.

Germination assay was performed according to $\mathrm{Ma}$ et al. (2005). Orobanche cumana seeds (20-40 seeds) were incubated on $8 \mathrm{~mm}$ moist glass-fiber filter paper at $30{ }^{\circ} \mathrm{C}$ for 7 days, and then $30 \mu \mathrm{l}$ diluted root exudates were applied to glass-fiber filter paper to stimulate seeds germination. Germination of the treated seeds was recorded after incubated at $30{ }^{\circ} \mathrm{C}$ for another week. Three replicates of each assay were performed and germination data were statistically analyzed using SPSS software.

\section{Determination of CKs concentration}

The tiller basal portion (about $0.5 \mathrm{~cm}$ ) from 30 seedlings of each OX line (OX1, OX2 and OX3) at 34 DAG were mixed, which were named as OX-M. Ri-M indicated the mixed tiller basal portion from 30 seedlings of each RNA interference lines (Ri1, Ri2 and Ri3) at 34 DAG. Then CKs content were measured by MetWare (http://www.metware.cn/) based at ABSciexQTRAP $^{\circ} 4500 \mathrm{LC}-\mathrm{MS} / \mathrm{MS}$ platform among different genetically modified lines. Three replicates of each assay were performed.

\section{Additional files}

Additional file 1 Figure S1. OsNPF7.2 responded to nitrate specially, not to (TIFF $4917 \mathrm{~kb}$ ) ammonium. a Phenotypic analysis of seedlings (40 DAG) of transgenic lines.cultured under the $8 \mathrm{mM} \mathrm{NaNO}_{3}$. Bar $=10 \mathrm{~cm}$. b Seedlings (40 DAG) of WT, OX.lines, Ri lines and osnpf7.2 cultured under the $4 \mathrm{mM}\left(\mathrm{NH}_{4}\right)_{2} \mathrm{SO}_{4}$. Bar $=10 \mathrm{~cm}$. c-d.Statistical analysis of root length of

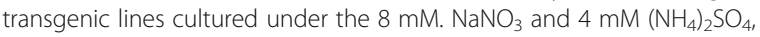
respectively. Date are shown as mean \pm SD $(n=10)$. From three replicates; "**" and "**" indicated significant differences at $P<0.05$ and $P .<0.01$, respectively.

Additional file 2 Figure S2. Transcript abundance of two glutamine synthetase GS1;2 and GS2 in tiller buds among transgenic lines. Date are shown as mean \pm SD from three replicates; "*", "*** and "***" indicated significant differences at $P<0.05, P<0.01$ and $P<0.001$, respectively. (TIFF 127 kb)

Additional file 3 Figure S3. Gemination rate of Orobanche cumana seeds. To estimated SLs levels among ZH11, OX lines, Ri lines and mutant osnpf7.2, root exudates of each line were applied to pre-incubated Orobanche cumana seeds. Date are shown as mean \pm SD from three replicates; $^{~ " * " ~ i n d i c a t e d ~ s i g n i f i c a n t ~ d i f f e r e n c e s ~ a t ~} P<0.05$. (TIFF $4595 \mathrm{~kb}$ )

Additional file 4 Table S1. Primers used in this study.

\section{Abbreviations}

CK: Cytokinin; DAG: Days after germination; OX: Over-expression; OX-M: Overexpression lines mixed; Ri: RNA-interference; Ri-M: RNA-interference lines mixed; SL: Strigolactone; WT: Wild type

\section{Acknowledgments}

The authors would like to thank Prof. Yongqing Ma and Lectuer Chao Zhang (North West Agriculture and Forestry University) for kindly providing Orobanche cumana seeds.

\section{Statistical analysis}

Two-tailed Student's $t$ tests were performed using the SPSS 10 software (IBM, Inc.). ${ }^{\prime *},{ }^{* *}$ and ${ }^{* * *}$ indicate significance at $P<0.05, P<0.01$ and $P<0.001$, respectively.

\section{Funding}

This research was supported by grants from the National Natural Science Foundation (31301250, 31701990), the National Key Research and Development Program (2016YFD01007), the open project of State Key Laboratory of Rice Biology (160203), Hubei Natural Science Foundation (2017CFB696), Chinese Postdoctoral Science Foundation (2015 M582243), and the Scientific research projects of Hubei Education Department (B2017293).

\section{Availability of data and materials}

All data supporting the conclusions of this article are provided within the article (and its additional files).

\section{Authors' contributions}

ZF and JW designed this study. JW, $\mathrm{KL}$ and $\mathrm{HN}$ performed the experiments of $\mathrm{NO}_{3}^{-}$influx and concentration, total $\mathrm{N}$ content, CKs concentration measurements, root exudates extraction, germination assay of Orobanche cumana seeds, and qRT-PCR analysis. QZ and JW investigated length of tiller buds in transgenic lines. ZF, QZ, BW and JQ constructed the transgenic lines and took care of rice lines. JW and ZF performed the statistical analysis and wrote the manuscript. All authors read and approved the final manuscript.

\section{Ethics approval and consent to participate}

Not applicable.

\section{Consent for publication}

Not applicable.

\section{Competing interests}

The authors declare that they have no competing interests. 


\section{Publisher's Note}

Springer Nature remains neutral with regard to jurisdictional claims in published maps and institutional affiliations.

Received: 12 September 2017 Accepted: 21 February 2018 Published online: 27 February 2018

\section{References}

Arite T, Iwata H, Ohshima K, Maekawa M, Nakajima M, Kojima M, Sakakibara H, Kyozuka J (2007) DWARF10, an RMS1/MAX4/DAD1 ortholog, controls lateral bud outgrowth in rice. Plant J 51:1019-1029

Arite T, Umehara M, Ishikawa S, Hanada A, Maekawa M, Yamaguchi S, Kyozuka J (2009) D14, a strigolactone-insensitive mutant of rice, shows an accelerated outgrowth of tillers. Plant Cell Physiol 50:1416-1424

Cai H, Zhou Y, Xiao J, Li X, Zhang Q, Lian X (2009) Overexpressed glutamine synthetase gene modifies nitrogen metabolism and abiotic stress responses in rice. Plant Cell Rep 28:527-537

Carleton KL (2011) Quantification of transcript levels with quantitative RT-PCR. Methods Mol Biol 772:279-295

Chen Z, Yamaji N, Horie T, Che J, Li J, An G, Ma J (2017) A magnesium transporter OsMGT1 plays a critical role in salt tolerance in Rice. Plant Physiol 174:1837-1849

Domagalska MA, Leyser O (2011) Signal integration in the control of shoot branching. Nat Rev Mol Cell Biol 12:211-221

Fan X, Xie D, Chen J, Lu H, Xu Y, Ma C, Xu G (2014) Over-expression of OsPTR6 in rice increased plant growth at different nitrogen supplies but decreased nitrogen use efficiency at high ammonium supply. Plant Sci 227:1-11

Fang Z, Bai G, Huang W, Wang Z, Wang X, Zhang M (2017) The rice peptide transporter OsNPF7.3 is induced by organic nitrogen, and contributes to nitrogen allocation and grain yield. Front plant Sci 8:1338

Fang Z, Xia K, Yang X, Grotemeyer MS, Meier S, Rentsch D, Xu X, Zhang M (2013) Altered expression of the PTR/NRT1 homologue OsPTR9 affects nitrogen utilization efficiency, growth and grain yield in rice. Plant Biotechnol I 11:446-458

Ferguson BJ, Beveridge CA (2009) Roles for auxin, cytokinin, and strigolactone in regulating shoot branching. Plant Physiol 149:1929-1944

Gomez-Roldan V, Fermas S, Brewer PB, Puech-Pages V, Dun EA, Pillot JP, Letisse F, Matusova R, Danoun S, Portais JC, Bouwmeester H, Becard G, Beveridge CA, Rameau C, Rochange SF (2008) Strigolactone inhibition of shoot branching. Nature 455:189-194

Guo S, Xu Y, Liu H, Mao Z, Zhang C, Ma Y, Zhang Q, Meng Z, Chong K (2013) The interaction between OsMADS57 and OsTB1 modulates rice tillering via DWARF14. Nat Commun 4:1566

Hachiya T, Sakakibara H (2017) Interactions between nitrate and ammonium in their uptake, allocation, assimilation, and signaling in plants. J Exp Bot 68: $2501-2512$

Hayward A, Stirnberg P, Beveridge C, Leyser O (2009) Interactions between auxin and strigolactone in shoot branching control. Plant Physiol 151:400-412

He YN, Peng JS, Cai Y, Liu DF, Guan Y, Yi HY, Gong JM (2017) Tonoplast-localized nitrate uptake transporters involved in vacuolar nitrate efflux and reallocation in Arabidopsis. Sci Rep 7:6417

Hiei Y, Komari T, Kubo T (1997) Transformation of rice mediated by agrobacterium tumefaciens. Plant Mol Biol 35:205-218

Hu B, Wang W, Ou S, Tang J, Li H, Che R, Zhang Z, Chai X, Wang H, Wang Y, Liang C, Liu L, Piao Z, Deng Q, Deng K, Xu C, Liang Y, Zhang L, Li L, Chu C (2015) Variation in NRT1.1B contributes to nitrate-use divergence between rice subspecies. Nat Genet 47:834-838

Hu R, Qiu D, Chen Y, Miller AJ, Fan X, Pan X, Zhang M (2016) Knock-down of a tonoplast localized low-affinity nitrate transporter OsNPF7.2 affects Rice growth under high nitrate supply. Front plant Sci 7:1529

Ishikawa S, Maekawa M, Arite T, Onishi K, Takamure I, Kyozuka J (2005) Suppression of tiller bud activity in tillering dwarf mutants of rice. Plant Cell Physiol 46:79-86

Jiang L, Liu X, Xiong G, Liu H, Chen F, Wang L, Meng X, Liu G, Yu H, Yuan Y, Yi W, Zhao L, Ma H, He Y, Wu Z, Melcher K, Qian Q, Xu HE, Wang Y, Li (2013) DWARF 53 acts as a repressor of strigolactone signalling in rice. Nature 504:401-405

Khush GS (2005) What it will take to feed 5.0 billion rice consumers in 2030. Plant Mol Biol 59:1-6

Koumoto T, Shimada H, Kusano H, She KC, Iwamoto M, Takano M (2013) Rice monoculm mutation moc2, which inhibits outgrowth of the second tillers, is ascribed to lack of a fructose-1, 6-bisphosphatase. Plant Biotech 30:47-56
Kulkarni KP, Vishwakarma C, Sahoo SP, Lima JM, Nath M, Dokku P, Gacche RN, Mohapatra T, Robin S, Sarla N, Seshashayee M, Singh AK, Singh K, Singh NK, Sharma RP (2014) A substitution mutation in OsCCD7 cosegregates with dwarf and increased tillering phenotype in rice. J Genet 93:389-401

Leyser O (2003) Regulation of shoot branching by auxin. Trends Plant Sci 8:541-545

Li H, Hu B, Chu C (2017) Nitrogen use efficiency in crops: lessons from Arabidopsis and rice. J Exp Bot 68:2477-2488

Li X, Qian Q, Fu Z, Wang Y, Xiong G, Zeng D, Wang X, Liu X, Teng S, Hiroshi F, Yuan M, Luo D, Han B, Li J (2003) Control of tillering in rice. Nature 422:618-621

Li Y, Ouyang J, Wang YY, Hu R, Xia K, Duan J, Wang Y, Tsay YF, Zhang M (2015) Disruption of the rice nitrate transporter OsNPF2.2 hinders root-to-shoot nitrate transport and vascular development. Scientific reports 5:9635

Liang WH, Shang F, Lin QT, Lou C, Zhang J (2014) Tillering and panicle branching genes in rice. Gene 537:1-5

Lin CM, Koh S, Stacey G, Yu SM, Lin TY, Tsay YF (2000) Cloning and functional characterization of a constitutively expressed nitrate transporter gene, OsNRT1, from rice. Plant Physiol 122:379-388

Lin H, Wang R, Qian Q, Yan M, Meng X, Fu Z, Yan C, Jiang B, Su Z, Li J, Wang Y (2009) DWARF27, an iron-containing protein required for the biosynthesis of strigolactones, regulates rice tiller bud outgrowth. Plant Cell 21:1512-1525

Lin Q, Wang D, Dong H, Gu S, Cheng Z, Gong J, Qin R, Jiang L, Li G, Wang JL, Wu F, Guo X, Zhang X, Lei C, Wang H, Wan J (2012) Rice APC/C (TE) controls tillering by mediating the degradation of MONOCULM 1. Nat Commun 3:752

Lu Z, Shao G, Xiong J, Jiao Y, Wang J, Liu G, Meng X, Liang Y, Xiong G, Wang Y, Li J (2015) MONOCULM 3, an ortholog of WUSCHEL in rice, is required for tiller bud formation. J Genet Genomics 42:71-78

Ma Y, Shui J, Inanaga S, Cheng J (2005) Stimulatory effects of Houttuynia cordata Thunb. On seed germination of Striga hermonthica (Del.) Benth. Allelopathy J 15:49-56

Minakuchi K, Kameoka H, Yasuno N, Umehara M, Luo L, Kobayashi K, Hanada A Ueno K, Asami T, Yamaguchi S, Kyozuka J (2010) FINE CULM1 (FC1) works downstream of strigolactones to inhibit the outgrowth of axillary buds in rice. Plant Cell Physiol 51:1127-1135

Mjomba FM, Zheng Y, Liu H, Tang W, Hong Z, Wang F, Wu W (2016) Homeobox is pivotal for OsWUS controlling tiller development and female fertility in Rice. G3 (Bethesda) 6:2013-2021

Ohashi M, Ishiyama K, Kojima S, Kojima M, Sakakibara H, Yamaya T, Hayakawa T (2017) Lack of cytosolic glutamine Synthetase1;2 activity reduces nitrogendependent biosynthesis of Cytokinin required for axillary bud outgrowth in Rice seedlings. Plant Cell Physiol 58:679-690

Oikawa T, Kyozuka J (2009) Two-step regulation of LAX PANICLE1 protein accumulation in axillary meristem formation in Rice. Plant Cell 21:1095-1108

Riou-Khamlichi C, Huntley R, Jacqmard A, Murray JA (1999) Cytokinin activation of Arabidopsis cell division through a D-type cyclin. Science 283:1541-1544

Ruyter-Spira C, Al-Babili S, van der Krol S, Bouwmeester H (2013) The biology of strigolactones. Trends Plant Sci 18:72-83

Shimizu-Sato S, Tanaka M, Mori H (2009) Auxin-cytokinin interactions in the control of shoot branching. Plant Mol Biol 69:429-435

Tabuchi H, Zhang Y, Hattori S, Omae M, Shimizu-Sato S, Oikawa T, Qian Q, Nishimura M, Kitano H, Xie H, Fang X, Yoshida H, Kyozuka J, Chen F, Sato Y (2011) LAX PANICLE2 of rice encodes a novel nuclear protein and regulates the formation of axillary meristems. Plant Cell 23:3276-3287

Takeda T, Suwa Y, Suzuki M, Kitano H, Ueguchi-Tanaka M, Ashikari M, Matsuoka M, Ueguchi C (2003) The OsTB1 gene negatively regulates lateral branching in rice. Plant J 33:513-520

Tang Z, Chen Y, Chen F, Ji Y, Zhao FJ (2017) OsPTR7 (OsNPF8.1), a putative peptide transporter in Rice, is involved in Dimethylarsenate accumulation in Rice grain. Plant Cell Physiol 58:904-913

Turnbull CG, Raymond MA, Dodd IC, Morris SE (1997) Rapid increases in cytokinin concentration in lateral buds of chickpea (Cicer arietinum L.) during release of apical dominance. Planta 202:271-276

Umehara M, Hanada A, Yoshida S, Akiyama K, Arite T, Takeda-Kamiya N, Magome H, Kamiya Y, Shirasu K, Yoneyama K, Kyozuka J, Yamaguchi S (2008) Inhibition of shoot branching by new terpenoid plant hormones. Nature 455:195-200

Wang Y, Li J (2011) Branching in rice. Curr Opin Plant Biol 14:94-99

Wang Z, Chen C, Xu Y, Jiang R, Han Y, Xu Z, Chong K (2004) A practical vector for efficient knockdown of gene expression in rice (Oryza sativa L.) Plant Mol Bio Rep 22:409-417

Xia X, Fan X, Wei J, Feng H, Qu H, Xie D, Miller AJ, Xu G (2015) Rice nitrate transporter OsNPF2.4 functions in low-affinity acquisition and long-distance transport. J Exp Bot 66:317-331 
Xing Y, Zhang Q (2010) Genetic and molecular bases of rice yield. Annu Rev Plant Biol 61:421-442

Xu C, Wang Y, Yu Y, Duan J, Liao Z, Xiong G, Meng X, Liu G, Qian Q, Li J (2012) Degradation of MONOCULM 1 by APC/C(TAD1) regulates rice tillering. Nat Commun 3:750

Xu J, Zha M, Li Y, Ding Y, Chen L, Ding C, Wang S (2015) The interaction between nitrogen availability and auxin, cytokinin, and strigolactone in the control of shoot branching in rice (Oryza sativa L.) Plant Cell Rep 34:1647-1662

Yamaguchi M, Kato H, Yoshida S, Yamamura S, Uchimiya H, Umeda M (2003) Control of in vitro organogenesis by cyclin-dependent kinase activities in plants. Proc Natl Acad Sci U S A 100:8019-8023

Yamaya T, Kusano M (2014) Evidence supporting distinct functions of three cytosolic glutamine synthetases and two NADH-glutamate synthases in rice. J Exp Bot 65:5519-5525

Yang X, Chen L, He J, Yu W (2017) Knocking out of carotenoid catabolic genes in rice fails to boost carotenoid accumulation, but reveals a mutation in strigolactone biosynthesis. Plant Cell Rep 36:1533-1545

Yoneyama K, Awad A, Xie X, Yoneyama K, Takeuchi Y (2010) Strigolactones as germination stimulants for root parasitic plants. Plant Cell Physiol 51:1095-1103

Yoshida S, Kameoka H, Tempo M, Akiyama K, Umehara M, Yamaguchi S, Hayashi H, Kyozuka J, Shirasu K (2012) The D3 F-box protein is a key component in host strigolactone responses essential for arbuscular mycorrhizal symbiosis. New Phytol 196:1208-1216

Zhang Y, Van Dijk AD, Scaffidi A, Flematti GR, Hofmann M, Charnikhova T, Verstappen F, Hepworth J, van der Krol S, Leyser O, Smith SM, Zwanenburg B, Al-Babili S, Ruyter-Spira C, Bouwmeester HJ (2014) Rice cytochrome P450 MAX1 homologs catalyze distinct steps in strigolactone biosynthesis. Nat Chem Biol 10:1028-1033

Zhou F, Lin Q, Zhu L, Ren Y, Zhou K, Shabek N, Wu F, Mao H, Dong W, Gan L, Ma W, Gao H, Chen J, Yang C, Wang D, Tan J, Zhang X, Guo X, Wang J, Jiang L, Liu X, Chen W, Chu J, Yan C, Ueno K, Ito S, Asami T, Cheng Z, Lei C, Zhai H, Wu C, Wang H, Zheng N, Wan J (2013) D14-SCFD3-dependent degradation of D53 regulates strigolactone signalling. Nature 504:406-410

Zou J, Chen Z, Zhang S, Zhang W, Jiang G, Zhao X, Zhai W, Pan X, Zhu L (2005) Characterizations and fine mapping of a mutant gene for high tillering and dwarf in rice (Oryza sativa L.) Planta 222:604-612

Zou J, Zhang S, Zhang W, Li G, Chen Z, Zhai W, Zhao X, Pan X, Xie Q, Zhu L (2006) The rice HIGH-TILLERING DWARF1 encoding an ortholog of Arabidopsis MAX3 is required for negative regulation of the outgrowth of axillary buds. Plant J 48:687-698

Zurcher E, Muller B (2016) Cytokinin synthesis, signaling, and function-advances and new insights. Int Rev Cell Mol Biol 324:1-38

\section{Submit your manuscript to a SpringerOpen ${ }^{\circ}$ journal and benefit from:}

- Convenient online submission

- Rigorous peer review

- Open access: articles freely available online

- High visibility within the field

- Retaining the copyright to your article

Submit your next manuscript at $\gg$ springeropen.com 